Military Technical College

Kobry El-Kobbah,

Cairo, Egypt

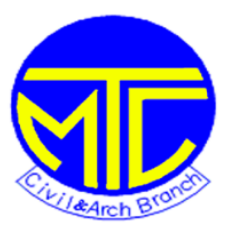

$12^{\text {th }}$ International Conference

on Civil and Architecture

Engineering

ICCAE-12-2018

\title{
Stability of SCSC Rectangular Plates under Intermediate and End Uniaxial
}

\section{Loads}

\author{
MAGDY ISRAEL SALAMA ${ }^{1}$
}

\begin{abstract}
This paper is concerned with a new buckling problem of rectangular plate subjected to uniaxial loads. The considered plate has two clamped edges parallel to $\mathrm{x}$-axis while the other edges parallel to $\mathrm{y}$-axis are simply supported (SCSC) subjected to combined uniaxial loads. The analysis of the plate under study is performed using minimum potential energy techniques andthe results are examined using finite element method. The energy method depends on the assumed deflection function, which satisfies exactly the end conditions and capable of representing the deflected plate surface. The analysis furnishes an approximate stability solutions; presented in curves describe the relation between the ratio of the intermediate load to the end load both, aspect ratio and the location of the intermediate load. These results can be used simply to design plates or walls that have to support intermediate floors/loads.Comparisons between the results of the energy technique and the finite element methods show very good agreement.
\end{abstract}

\section{KEYWORDS}

Stability;Rectangular plates; Intermediate load;Elastic analysis; Finite element; Energy approach. 


\section{Introduction}

The stability of thin elastic rectangular plates under uniaxial loads is an important problem in civil engineering and its applications.Solutions of such plates are documented in all standard texts on plate buckling (for example Timoshenko and Woinowsky [1], Szilard [2], Timoshenko and Gere [3]). In some practical applications, plates (or walls) may subject to both intermediate load/floor and end loads. Stability of such loaded plates is, however, not available in open literature and not studied except for a recent paper by Xiang and Wang[4]that used the Levy solution approach and the state-space technique to solve such a problem.

Also, Wang et al. [5]present some of the important features associated with the buckling of plates under combined uniaxial loads depending on the dividing of the considered plate into two sub-plates.Theexact critical buckling loadis the lowest solution of the combinationsof each subplate solutions. The lowest solution from the twenty five is. Thestudy by Wang et al. [5]includerectangular plate with two simply supported edges parallel to $\mathrm{x}$-axis while the other edges parallel to y-axis can be free, simply supported, or clamped.

Salama [6] presents an approximate solution for the buckling loads of simply supported plates only in case of end and intermediate loadsusing energy technique.

In this paper, anew case of study of SCSC rectangular plate under end and intermediate loads is investigated using both energy approach and finite element method.

\section{Model and Assumptions}

Consider anisotropic, elastic rectangular thin plate have two simply supported opposite edges parallel to y-axis (perpendicular to the load direction) and the other two opposite edges that parallel to $\mathrm{x}$-axis are clampededges as shown in Figure1.The plate is of length $a$, width $b$,thickness $h$, modulus of elasticity $E$ and Poisson's ratio $v$. The plate is subjected to an end 
uniaxial compressive load $N_{1}$ at left edge $(x=0)$, beside an intermediate compressive load $N_{2}$ at alocation $x=\beta a$.

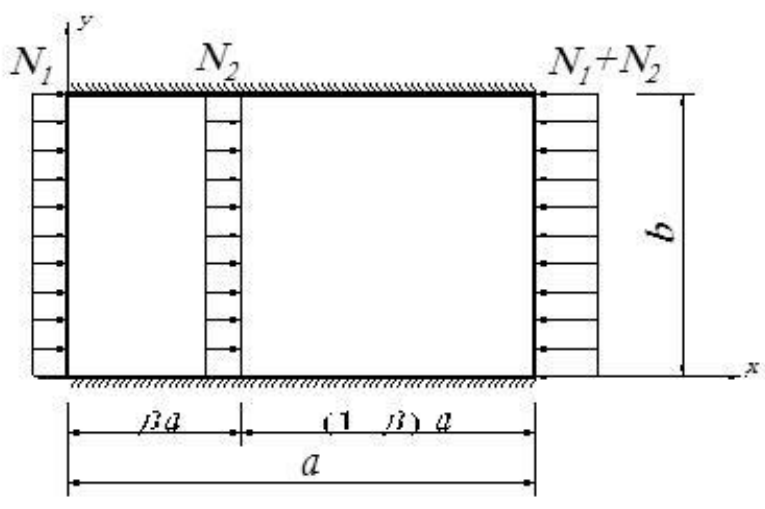

Figure1.Stability of SCSC rectangular plate under intermediate and end uniaxial loads

\section{Method of Analysis and Theoretical Equations}

The deflection function of the buckled SCSC rectangular platecan be taken in the form of the double trigonometric series

$$
w=\sum_{m=1}^{\infty} \sum_{n=1}^{\infty} C_{m n} \sin \frac{m \pi x}{a} \sin ^{2} \frac{n \pi y}{b}
$$

Where $C_{m n}$ are the unknown constants to be determined

The general expression in Equation (1)can be simplified by considering the plate buckled into one half-wave in $y$ direction $(n=1)$ and the buckled plate is subdivided along the $\mathrm{x}$-axis intomhalf waves ,the followingfunction can be taken

$$
w=\sin ^{2} \frac{\pi y}{b} \sum_{m=1}^{\infty} C_{m} \sin \frac{m \pi x}{a}
$$

The total strain energy, $U$, of the plate in bending can be expressed as follows 
$U=\frac{D}{2} \int_{0}^{b} \int_{0}^{a}\left[\left(\frac{\partial^{2} w}{\partial x^{2}}+\frac{\partial^{2} w}{\partial y^{2}}\right)^{2}-2(1-v)\left[\frac{\partial^{2} w}{\partial x^{2}} \frac{\partial^{2} w}{\partial y^{2}}-\left(\frac{\partial^{2} w}{\partial x \partial y}\right)^{2}\right]\right] d x d y$

Where $D=\left(E h^{3}\right) /\left(12(1-v)^{2}\right)$ is the flexural rigidity of the plate.

Also, the work, $T$, doneby the end uniaxial compressive load $N_{1}$ at edge $x=0$, and the intermediate compressive load $N_{2}$ at a location $x=\beta a$ is

$$
T=\frac{\left(N_{1}+N_{2}\right)}{2} \int_{0}^{b} \int_{0}^{a}\left(\frac{\partial w}{\partial x}\right)^{2} d x d y-\frac{\left(N_{2}\right)}{2} \int_{0}^{b} \int_{0}^{\beta a}\left(\frac{\partial w}{\partial x}\right)^{2} d x d y
$$

Substituting the deflection expressionin Equation (2) into Equations $(3,4)$,

$$
U=\frac{D \pi^{4}}{8 a b} \sum_{m=1}^{m=\infty} C_{m}^{2}\left(\frac{3 m^{4} b^{2}}{4 a^{2}}+\frac{4 a^{2}}{b^{2}}+2 m^{2}\right)
$$

And,

$$
T=\frac{3\left(N_{1}+N_{2}\right) \pi^{2} b}{32 a} \sum_{m=1}^{m=\infty}\left[m^{2} C_{m}^{2}\right]-\frac{3 N_{2} \pi^{2} b}{32 a}\left\{\sum_{m=1}^{m=\infty}\left[m^{2} C_{m}^{2}\left(\beta+S_{2 m}\right)+\sum_{i=1}^{m-1} \sum_{j=i+1}^{m} 2 i j C_{i} C_{j}\left(S_{j-i}+S_{j+i}\right)\right]\right\}
$$

Where, $S_{k}=\frac{\sin k \pi \beta}{k \pi}$

Then the total energy $(V)$ of the system is

$$
V=U-T
$$

Substituting Equations $(5,6)$ into Equation $(7)$, 


$$
\begin{aligned}
V=\frac{D \pi^{4}}{8 a b} \sum_{m=1}^{m=\infty} C_{m}^{2}\left(\frac{3 m^{4} b^{2}}{4 a^{2}}+\frac{4 a^{2}}{b^{2}}+2 m^{2}\right)-\frac{3\left(N_{1}+N_{2}\right) \pi^{2} b}{32 a} \sum_{m=1}^{m=\infty}\left[m^{2} C_{m}^{2}\right] \\
+\frac{3 N_{2} \pi^{2} b}{32 a}\left\{\sum_{m=1}^{m=\infty}\left[m^{2} C_{m}^{2}\left(\beta+S_{2 m}\right)+\sum_{i=1}^{m-1} \sum_{j=i+1}^{m} 2 i j C_{i} C_{j}\left(S_{j-i}+S_{j+i}\right)\right]\right\}
\end{aligned}
$$

Using the following expressions to the buckling factors for the end and intermediate loads

$$
A_{1}=\frac{N_{1} b^{2}}{\pi^{2} D} \quad \text { and } \quad A_{2}=\frac{N_{2} b^{2}}{\pi^{2} D}
$$

The total energy $(V)$ can be expressed as

$$
\begin{aligned}
V=\sum_{m=1}^{m=\infty} C_{m}^{2}\left(\frac{3 m^{4} b^{2}}{4 a^{2}}+\right. & \left.\frac{4 a^{2}}{b^{2}}+2 m^{2}\right)-\frac{3\left(A_{1}+A_{2}\right)}{4} \sum_{m=1}^{m=\infty}\left[m^{2} C_{m}^{2}\right] \\
& +\frac{3 A_{2}}{4}\left\{\sum_{m=1}^{m=\infty}\left[m^{2} C_{m}^{2}\left(\beta+S_{2 m}\right)+\sum_{i=1}^{m-1} \sum_{j=i+1}^{m} 2 i j C_{i} C_{j}\left(S_{j-i}+S_{j+i}\right)\right]\right\}
\end{aligned}
$$

This is a function of second degree with coefficients $C_{1}, C_{2}, \ldots \ldots C_{\mathrm{m}}$. These coefficients must now be chosen so as to make the total energy $(V)$ a minimum, from which it follows that

$$
\frac{\partial V}{\partial C_{1}}=0 \quad \frac{\partial V}{\partial C_{2}}=0 \quad \cdots \quad \frac{\partial V}{\partial C_{m}}=0
$$

This minimization procedure yieldsmhomogeneous linear equations in $C_{1}, C_{2}, \ldots, C_{m}$,whichcan be put in the following form

$[K]\{C\}=\{0\}$

In which $\{C\}=\left\{\mathrm{C}_{1}, \mathrm{C}_{2}, \ldots, \mathrm{C}_{\mathrm{m}}\right\}^{T}$ and the $(m \times m)$ coefficient matrix $[K]$ will be 
$[K]=\left[k_{i j}\right]_{m x m}$

Where,

$$
\begin{aligned}
& K_{i i}=\left(\frac{3 m^{4} b^{2}}{4 a^{2}}+\frac{4 a^{2}}{b^{2}}+2 m^{2}\right)-\frac{3}{4} i^{2}\left(A_{1}+A_{2}\right)+\frac{3}{4} i^{2} A_{2}\left(\beta+S_{2 i}\right) \quad \text { for } \quad i=j, \\
& K_{i j}=i A_{2}\left(S_{j-i}+S_{j+i}\right) \quad \text { for } \quad i \neq j, \quad i \prec j \\
& K_{i j}=j A_{2}\left(S_{i-j}+S_{j+i}\right) \quad \text { for } \quad i \neq j, \quad j \prec i
\end{aligned}
$$

These equations will be satisfied by putting $C_{1}, C_{2}, \ldots, C_{\mathrm{m}}$ equal to zero, which corresponds to the flat form of equilibrium of the plate. For a nontrivial solution, the buckling load of the plate can be obtained by equating to zero the determinate of $[K]$. By selecting the number of trigonometric series $(m)$ and assuming the intermediate force $N_{2}$, the end compressive force $N_{1}$ will be gradually increasing until arriving a value for which one of the coefficients $C_{1}, C_{2}$, $\ldots, C_{\mathrm{m}}$ becomes infinity. The smallest of these values of $N_{1}$ is called the end critical value corresponding to the assumed intermediate force $N_{2}$. This method of calculating the critical buckling load brings us to a closer and closer approximation as the number $(m)$ of the terms of the deflection function series given in Equation (3) increases, and by taking $(m)$ infinitely large we obtain an exact solution.

To examine the energy methodresults, finite element method is applied to the stability analysis of the considered plate. Mode shape for some cases of SCSC rectangular plates under intermediate load N2 are shown in figure 3 that describe the buckling behaviour of the plate under study. 


\section{Results and Discussions}

An approximate solutions for the stability of SCSC rectangular plates under both intermediate and end loads are presented in Figure (2) (a-c). These results cover various aspect ratios $(a / b=1,1.5$ and 2) and intermediate load locations $(\beta=0.3,0.5$ and 0.7$)$

From this figure, it is obvious that when the intermediate in-plane load is positive $\left(N_{2}>0\right)$, the buckling factor $A_{1}$ decrease almost linearly as the buckling factor $A_{2}$ increases for different aspect ratios. If the intermediate load is negative $\left(N_{2}<0\right)$, the buckling factor $A_{1}$ increases almost linearly as the value of the buckling factor $A_{2}$ increases. The increase of $A_{1}$ is more pronounced when the intermediate load location factor $\beta$ is small. It is evident that the stability curves shown in Figure (2) have a highly nonlinear portion when the buckling factor $A_{2}$ is close to zero.

Also, it can be noticed that when the intermediate in-plane load is absent $\left(N_{2}=0\right)$, the buckling factor $A_{1}$ is very close to the exact buckling factor for different aspect ratios $[1,3]$.

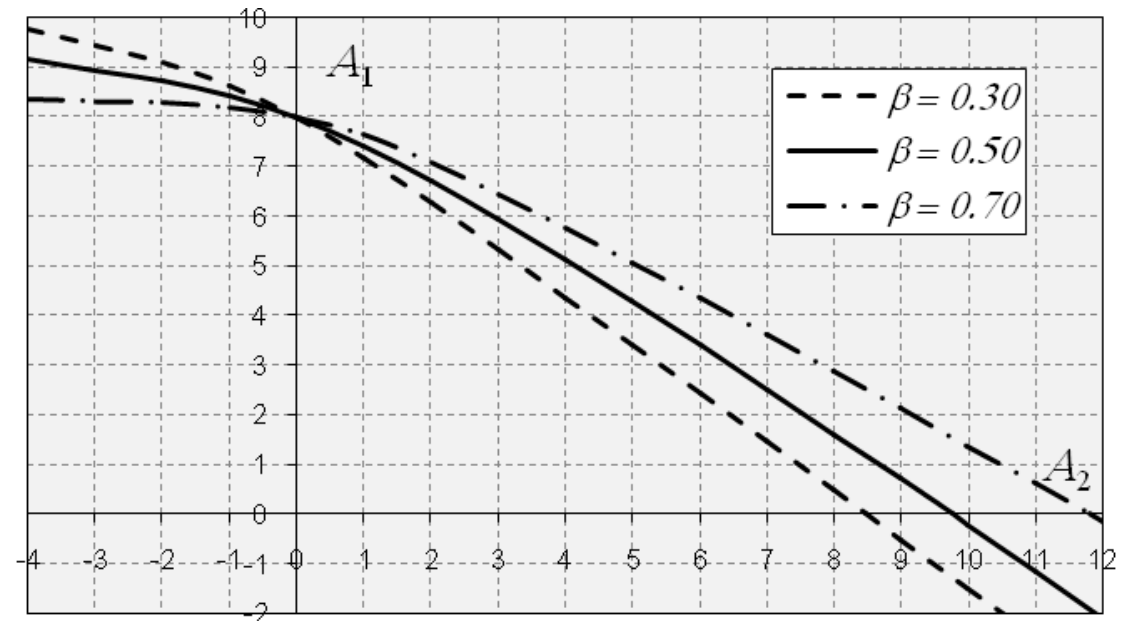

(a) Square plate $[a / b=1.0]$ 


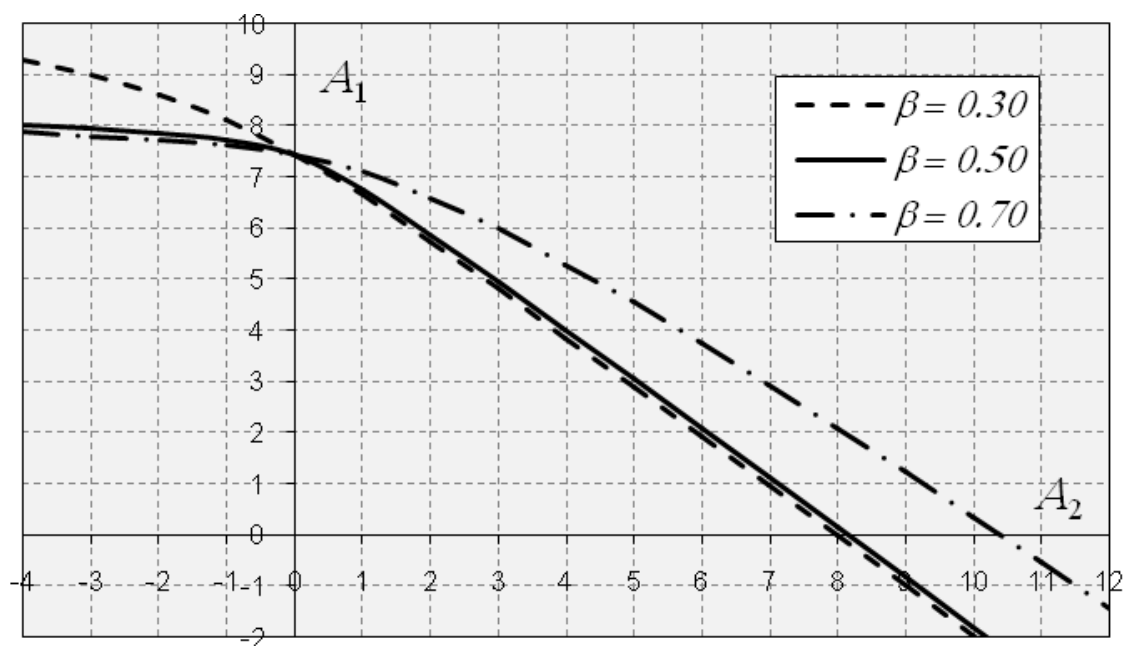

(b) Rectangular plate $[a / b=1.5]$

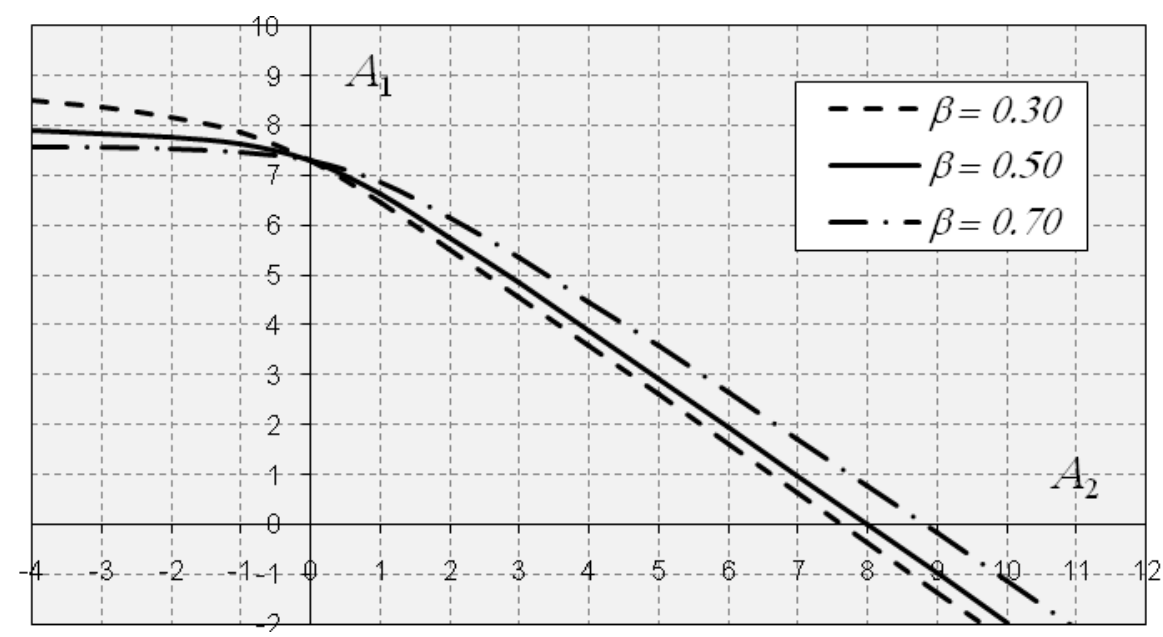

(c) Rectangular plate $[a / b=2.0]$

Figure2. Stability of SCSC rectangular plate under intermediate load $\mathrm{N}_{2}$ and end load $\mathrm{N}_{1}$ with aspect ratio (a) $a / b=1.0,(b) a / b=1.5$ and $(c) a / b=2.0$ 


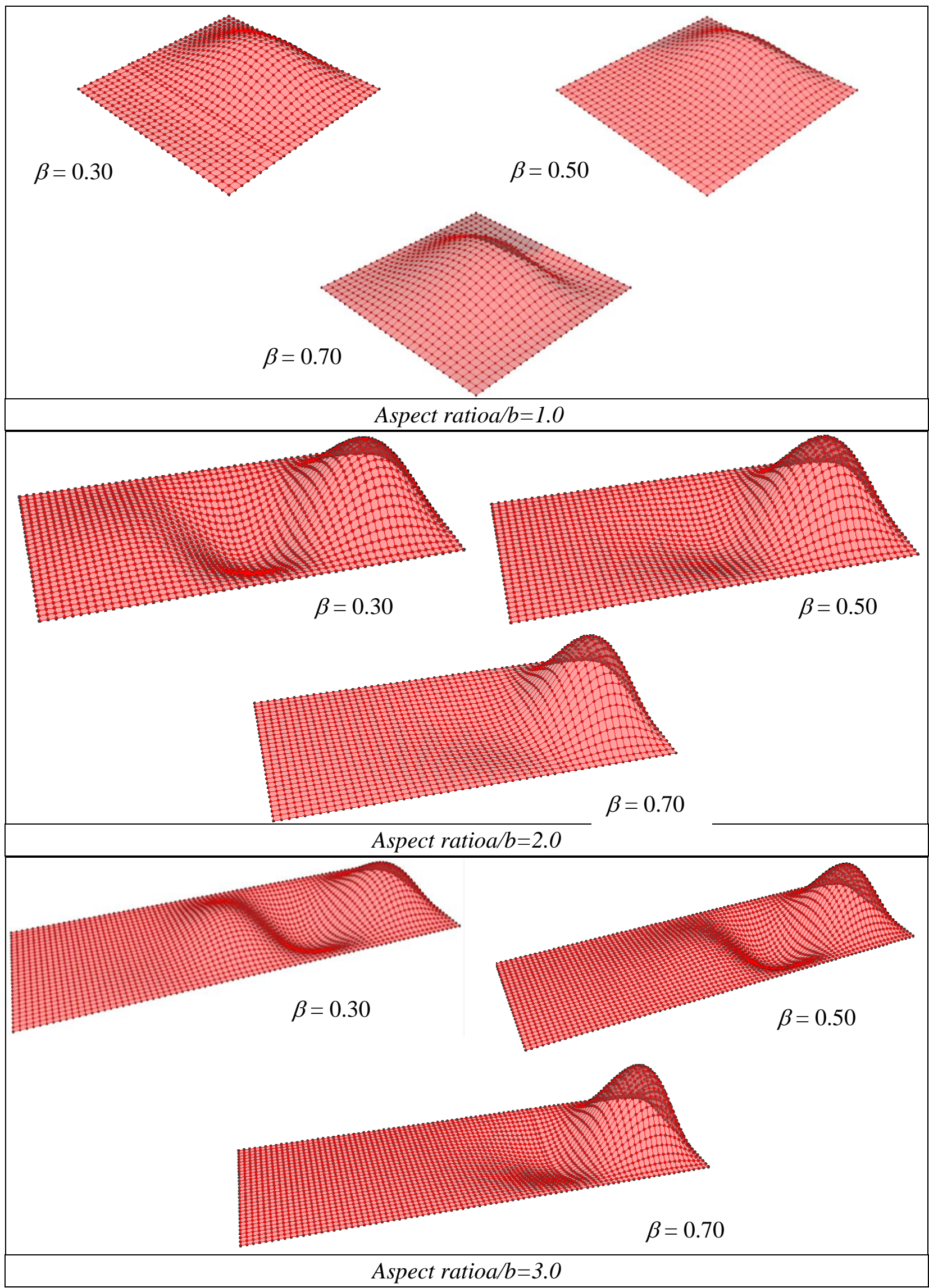

Figure3. Mode Shape for SCSC rectangular plate under intermediate load $\mathrm{N}_{2}$ 


\section{Comparison of the Results}

Table 1 shows the comparison between the energy approach and finite element method for theobtained buckling factor $A_{2}$ of SCSC rectangular plates subjected to intermediate in-plane load at $x=\beta a$ only. The values of the buckling factor $A_{2}$ were obtained assuming the number of trigonometric series terms equals to ten $(m=10)$.

Table 1.Comparison of buckling factor $\mathrm{A}_{2}$ obtained by energy approach with finite element method assuming the plate subjected to $N_{2}$ only $\left(N_{1}=0\right)$

\begin{tabular}{|c|c|c|c|c|}
\hline$a / b$ & $\beta$ & Finite Element Method & Energy Method & $\%$ Diff. \\
\hline & 0.30 & 8.1338 & 8.4534 & $3.93 \%$ \\
\hline \multirow[t]{3}{*}{1.00} & 0.50 & 9.2979 & 9.7398 & $4.75 \%$ \\
\hline & 0.70 & 11.4706 & 11.7983 & $2.86 \%$ \\
\hline & 0.30 & 7.4296 & 7.6260 & $2.64 \%$ \\
\hline \multirow[t]{3}{*}{2.00} & 0.50 & 7.7482 & 8.0024 & $3.28 \%$ \\
\hline & 0.70 & 8.4287 & 8.8038 & $4.45 \%$ \\
\hline & 0.30 & 7.3274 & 7.4602 & $1.81 \%$ \\
\hline \multirow[t]{2}{*}{3.00} & 0.50 & 7.4006 & 7.5858 & $2.50 \%$ \\
\hline & 0.70 & 7.7488 & 7.9771 & $2.95 \%$ \\
\hline
\end{tabular}

The comparison showed in the Table (1) clears the accuracy of the energy method that can be considered simple compared with the finite element method. 


\section{Conclusions}

An approximate solution for the buckling loads of SCSC plates subjected to both the end and intermediate in plane loads is presented in this paper using the energy approach and the obtained results are verified by applying the finite element method.

In this paper, the energy method is presented in form allowing use a large number of terms of the trigonometric series which represent the deflection of the buckled plate under study.

The great advantage of the present method is the determination of the critical buckling loads of the problem in hand from one solution.

This present method is simple to use by engineers designing walls or plates that have to support intermediate floor/loads with satisfactory accuracy.

\section{References}

[1] Timoshenko, S. P. and Woinowsky, K., (1987) “Theory of Plates and Shells”, McGrawHill Book Company, London.

[2] Szilard, R. (2004) "Theories and Applications of Plate Analysis: classical, numerical and engineering methods", John Wiley \& Sons, Inc, Hoboken, New Jersey.

[3] Timoshenko, S. P., and Gere, J. M. (1983) “Theory of Elastic Stability”, McGraw-Hill Book Company, London.

[4] Xiang Y., Wang C. M., and Kitipornchai S., (2003) "Exact Buckling Solutions for Rectangular Plates under Intermediate and End Uniaxial Loads”, Journal of Engineering Mechanics, ASCE ; 59:197-204.

[5] Wang C. M., Chen Y., and Xiang Y., (2004) "Stability Criteria for Rectangular Plates Subjected to Intermediate and End Inplane Loads", Journal of Thin-Walled Structures, Elsevier; 42:119-136. 
[6] Salama, M., I., (2012) "Approximate buckling solutions for rectangular plates under intermediate and end uniaxial loads", $10^{\text {th }}$ International Congress on Advances in Civil Engineering, Ankara, TURKEY, 17-19 October. 